\title{
Covif $-930405--33$
}

\section{UCRL-JC-113814 \\ PREPRINT}

\section{Development of Robust Multilayer Optics for Use in}

High-Peak Power Radiation Environments

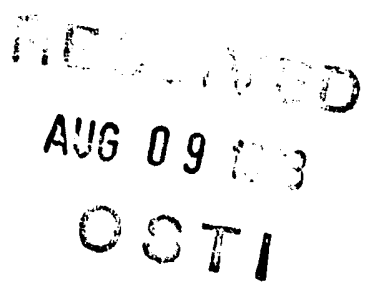

Brian J. MacGowan, S. Mrowka, T.W. Barbee Jr., L.B. DaSilva, D.C. Eder, J.A. Koch, J.A. Turner, and J.H. Underwood

\section{INERTIAL CONFINEMENT FUSION PROGRAM}

This paper prepared for submittal to Materials Research Society Spring Meeting

San Francisco, CA - April 12-16, 1993

\section{July 1993}

This is a preprint of a paper intended for publication in a journal or proceedings. Since changes may be made before publication, this preprint is made available with the understanding that it will not be cited or reproduced without the permission of the author.

\section{MASTER}

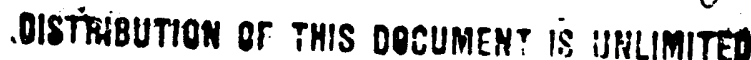




\section{DISCLAIMER}

This document was prepared as an account of work sponsored by an agency of the United States Government. Neither the United States Government mor the University of California nor any of their employees, makes any warranty, express or implied, or assumes any legal liability or responsibility for the accuracy, completeness, or usefulness of any information, apparatus, product, or process disclosed, or represents that its use would not infringe privately owned rights. Reference herein to any specific commercial products, process, or service by trade name, trademark, manufacturer, or otherwise, does not necessarily constitute or imply its endorsement, recommendation, or favoring by the United States Government or the University of California. The views and opinions of authors expressed herein do not necessarily state or reflect those of the United States Government or the University of Califomia, and shall not be used for advertising or product endorsement purposes. 


\title{
DEVELOPMENT OF ROBUST MULTILAYER OPTICS FOR USE IN HIGH- PEAK POWER RADIATION ENVIRONMENTS
}

\author{
BRIAN J. MACGOWAN*, S. MROWKA*, T.W. BARBEE JR.*, L. B. DA SILVA*, \\ D.C. EDER*, J.A. KOCH*, J.A. TURNER*, AND J. H. UNDERWOOD** \\ *Lawrence Livermore National Laboratory, University of California, L-476, P.O. Box 808, \\ Livermore, CA 94550, U.S.A. \\ ${ }^{* *}$ Lawrence Berkeley Laboratory, 1 Cyclotron Road, Bldg 2-400, Berkeley, CA 94720, U.S.A.
}

\section{ABSTRACT}

In many applications, $x$-ray multilayer mirrors are exposed to high peak fluxes of $x$-rays with subsequent damage to the mirror. Mirror damage is a particularly severe problem with the use of muitilayers as cavity optics for short wavelength $x$-ray lasers. Intense optical and $x$-ray radiation, from the $x$-ray laser plasma amplifier, often damage the multilayer mirror on time scales of hundreds of picoseconds. The phenomenon of multilayer mirror damage by pulsed $x-$ ray emission has been studied using short duration $(500 \mathrm{psec})$ bursts of soft $x$-rays from a laser produced gold plasma. The results of the experiments will be compared with some simple models and the possibility of increasing the damage thresholds of short wavelength multilayer mirrors will be discussed.

\section{INTRODUCTION}

One goal of the $x$-ray laser experiments at the Nova laser facility, is to develop a bright source of $x$-rays at a wavelength close to $45 \AA$, for use in biological imaging. To boost the output of the $\mathrm{Ni}$-like Ta $\mathrm{x}$-ray laser (at $44.83 \AA)^{1}$ we have attempted, unsuccessfully, to use a normal incidence $\mathrm{WC} / \mathrm{C}$ multilayer mirror to reflect the $\mathrm{x}$-ray laser emission back into the gain medium for "double pass" amplification. Several problems have been identified. The short duration of the gain in the amplifier means that" in order to benefit from the return pass, the mirror must be $2 \mathrm{~cm}$ or less from the end of the amplifier. At this distance, visible light fluences of up to $5 \mathrm{Jcm}^{-2}$ and $\mathrm{x}$-ray fluences of up to $0.24 \mathrm{Jcm}^{-2}$ have been measured in times of $250 \mathrm{psec}$, these fluences are high enough to damage the mirror. The spectrum of the damaging $x$-rays has been measured ${ }^{2}$ and shown to peak at photon energies between 250 and $500 \mathrm{eV}$. The source of the $x$-rays is both line emission and broad-band continuum from the high- $Z$ Ta plasma ( an estimated fluence of 0.03 $\mathrm{Jcm}^{-2}$ is due to the 44.83 - $\AA \mathrm{x}$-ray laser line.) We have evidence that WC/C mirrors placed $2 \mathrm{~cm}$ from the $x$-ray laser plasma, damage prior to the build up of $x$-ray laser gain $(\sim 250$ psec after the start of the experiment) and are therefore not able to reflect the $x$-ray laser. To predict how long different multilayer mirrors will survive, we need a more precise knowledge of the damage thresholds of candidate mirrors.

Ref 2 contains a review of previous work in the field of pulsed $x$-ray damage to multilayer mirrors. Most of the experiments described had limited spectulal and temporal resolution, making them insensitive to changes in the mirror period and peak mirror reflectivity, quantities that are crucial in determining the mirror reflection efficiency for a narrow band source such as an $x$-ray laser. Previous experiments to measure the $\mathrm{x}$-ray damage thresholds of $\mathrm{W} / \mathrm{C}$ and $\mathrm{WC} / \mathrm{C}$ multilayer mirrors have used high $x$-ray photon energies $(\sim 1 \mathrm{keV})^{3-5}$ and/or long timescale ( 1 $70 \mathrm{nsec}$ ) damage pulses $\mathrm{s}^{3-7}$ to irradiate the mirrors and are not directly applicable to our problem. As Hockaday pointed out, ${ }^{3}$ experiments performed on time scales of over a nsec would see higher damage thresholds due to heat conduction into the mirror substrate. In our $x$-ray laser experiments the time scales are much shorter and heat conduction is ineffective at cooling the mirrors. Furthermore almost all previous work used hard $(\sim 1 \mathrm{keV}) \mathrm{x}$-rays at near grazing incidence to probe the mirrors as they damaged, requiring some kind of extrapolation to predict the performance at normal incidence, a process that is known to be unreliable. ${ }^{8}$ Hence for the work described here and in Ref. 2 we probed the multilayers at near normal incidence and with sufficient time and spectral resolution in order to be able to observe any changes in the multilayer that would have significance for our $x$-ray laser experiments. 


\section{EXPERIMENT}

To quantify the $x$-ray damage thresholds of different mirror materials and to provide a database for comparison with numerical simulation we performed experiments at the Physics Research Laser (Janus) using shor duration (500 psec) bursts of soft $x$-rays from a laser produced plasma as the damage source. (Fig. 1) Two bearns of the Janus laser were used. The first (probe) beam irradiated a tungsten target with 5 Joules in a $1.3 \mathrm{nsec}$ pulse focused in a 400 $\mu \mathrm{m}$ diameter spot, resulting in the formation of an $x$-ray emitting plasma at the surface of the target. These probe $x$-rays were reflected, at near normal incidence, off the multilayer mirror under test and analyzed with a time resolved flat field grating spectrometer. 9 The spectrum emitted by the $W$ plasma was quasicontinuous at the resolution $(1 / \mathrm{Dl} \sim 200)$ of the spectrometer. Hence the reflected continuuin mapped out the normal incidence reflection characteristics of the multilayer as a function of time and $x$-ray wavelength. Measurement of the wavelength of the peak of the reflection bandpass allowed the period of the multilayer to be detormined while the width and shape of the bandpass provided information about the stack uniformity. Note that the mirror characterization was both at normal incidence and close to the wavelength at which the mirror would be used in an $x$-ray laser experiment.

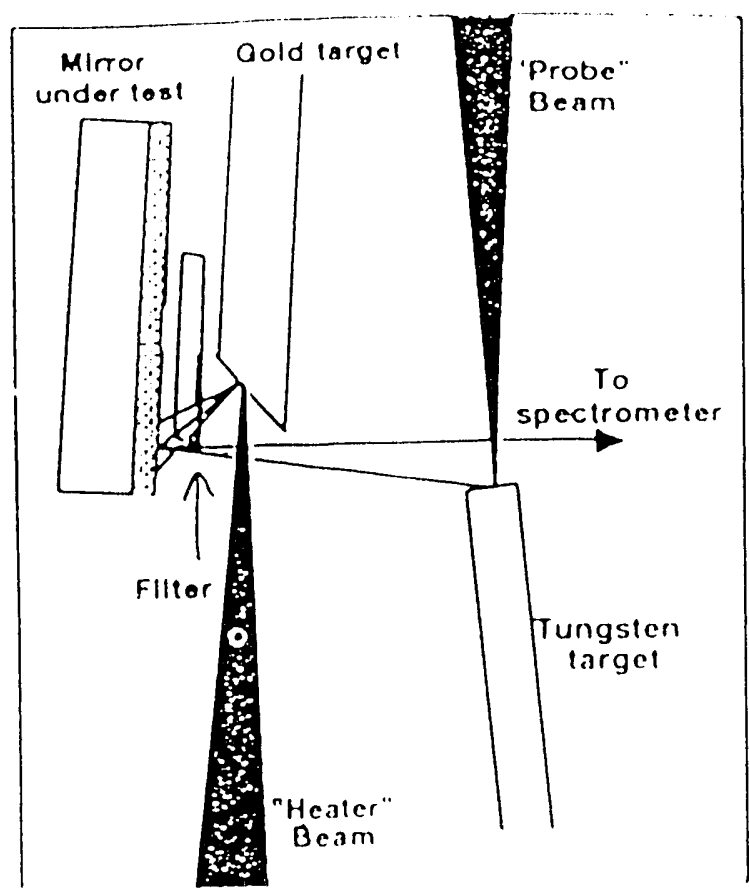

Fig. I Diagram of the experimental set-up showing the mirror under test, the gold coated target that produced the damaging $x$ rays and the tungsten target that produced the continuum $x$-rays used to probe the mirror. The spectrometer analysed the $x$ rays reflecting off the mirror at fixed angle of incidence ( $1^{\circ}$ off normal). Also shown is the thin aluminized Lexan filter that prevented visible light from the gold plasma striking the mirror.

A second beam (the heater beam) was then used to irradiate a gold target with up to 5() $\mathrm{J}$ of $2 \mathrm{w}$ light in a 500 psec pulse, producing a 500 psec duration burst of damaging $x$-rays. A thin filter consisting of $250 \AA$ of Al coated on $1000 \AA$ of Lexan was placed between the Au plasma and the mirror, in order to exclude optical light. The multilayer mirror was $11 \mathrm{~mm}$ from the Au target to maximize the $x$-ray fluence incident on the mirror while allowing space for the filter and passage of the probe $x$-rays. The $x$-ray damage pulse duration and spectral content were chosen to mimic the burst of $x$-rays that was damaging the mirrors in the Nova experiments. ${ }^{2}$

Sample data is shown in Fig 2(a) where a WC/C mirror (150) layer pairs with a period of $\sim 23 \AA$ per layer pair) reflects the $W$ spectrum close to $45 \AA$. Bright areas of exposure indicate wavelengths that are reflected by the multilayer. The duration of the reflected signal is being set by the $1.3 \mathrm{nsec}$ probe beam pulse which was fired to characterize the mirror in its undamaged state. Fig. 2(b) illustrates the effect on the mirror of simultaneously firing the heater beam. The second beam produced a total of $0.38 \mathrm{Jcm}^{-2}$ of damaging $x$-rays in a 50() psec Gaussian pulse, centered at $\mathrm{t}=0$. The reflected signal changes dramatically, at $\mathrm{t}=-200 \mathrm{psec}$, well before the peak of the heating pulse, and after the mirror has seen an integrated fluence of only $0.07 \mathrm{Jcm}^{-2}$ of $x$-rays. The $x$-ray flux incident on the multilayer was quantified using a calibrated diamond photo-conductive detector. ${ }^{10}$ 


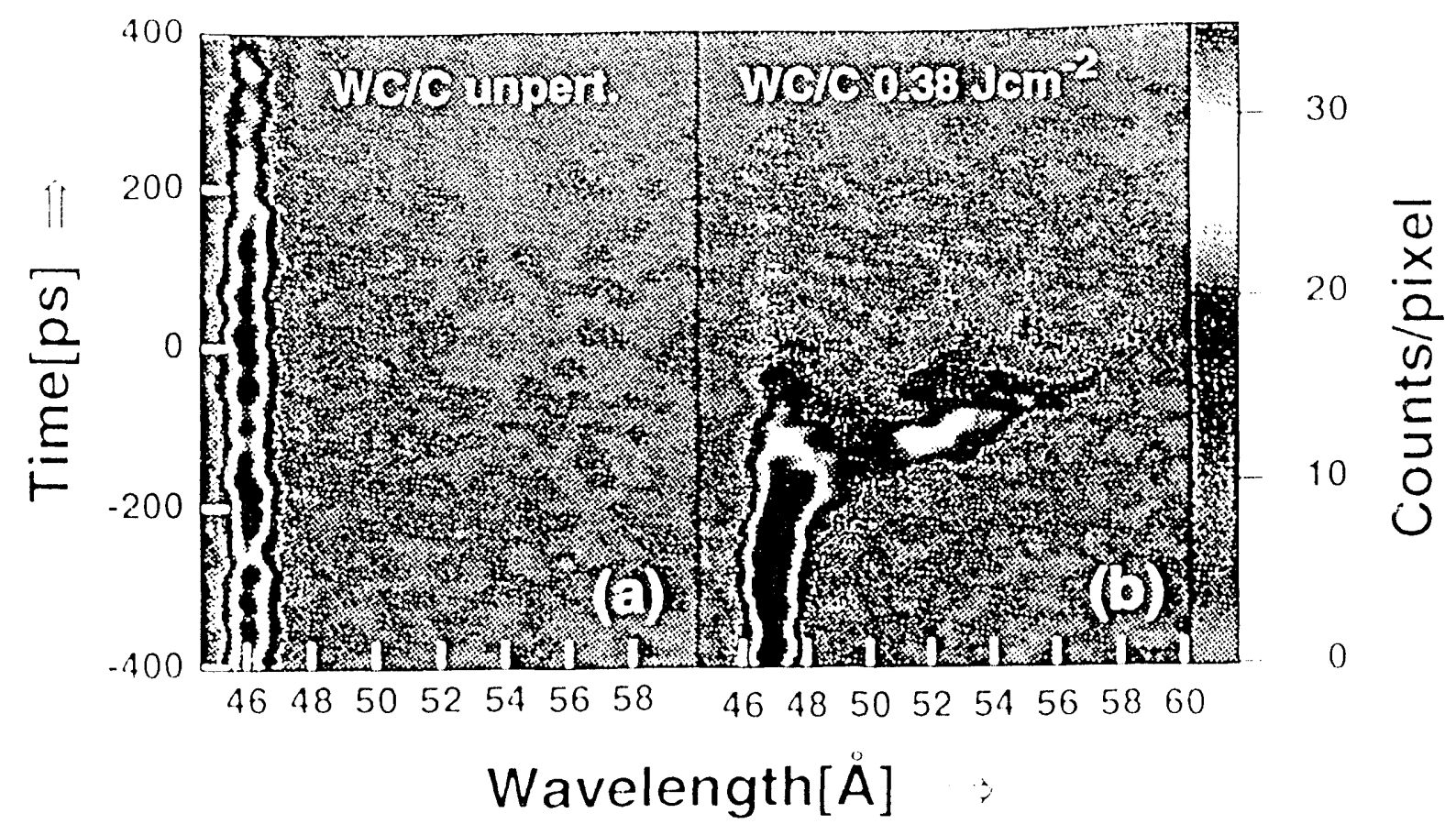

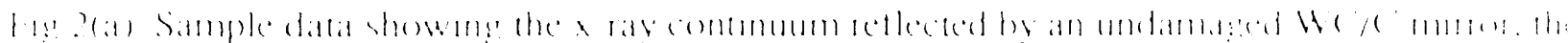

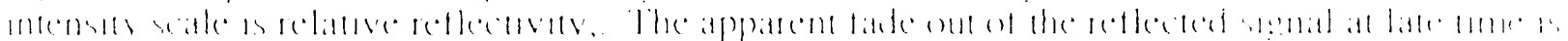

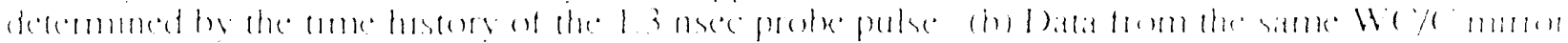

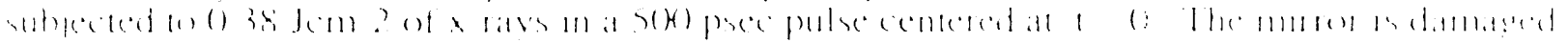

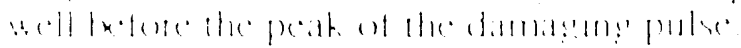

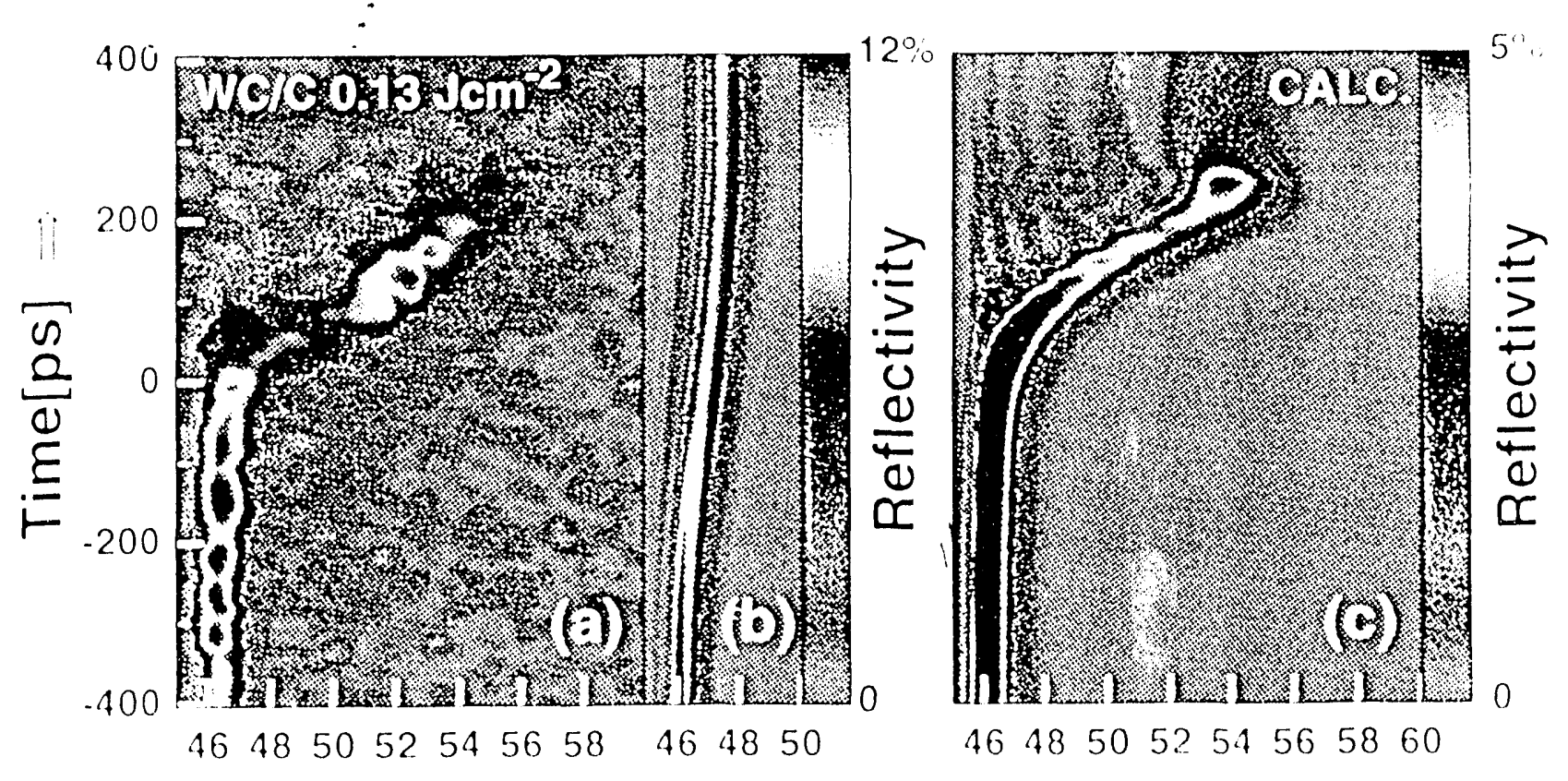

\section{Wavelength $[\mathrm{A}]$}

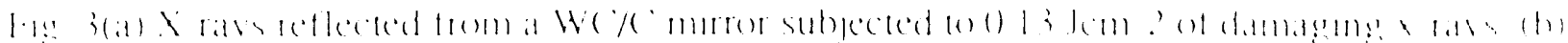

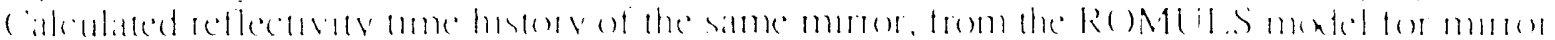

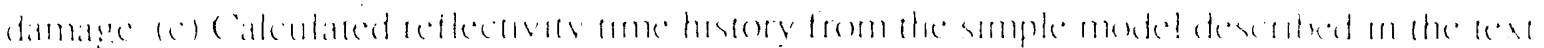




\section{RESULTS}

The damage response of many carbon based mirrors that reflected wavelengths close to $45 \AA$, at normal incidence, were measured with the above technique over a wide range of $x$-ray fluence, the results were reported in Ref. 2 . Fig 3(a) shows the data from a WC/C multilayer subjected to $0.13 \mathrm{Jcm}^{-2}$ of damaging $x$-rays in a 500 psec pulse, the lower total fluence leads to damage occurring later in the pulse compared with Fig 2(b) but after a similar integrated nuence (().)8 $\mathrm{Jcm}^{-2}$ ). The movement of the bandpass to longer wavelength is of similar magnitude to that of Fig 2(a) but occurs at a slower rate due to the lower instantaneous damaging flux.

In both Figs 2(b) and 3(a) we see similar behavior. The mirror bandpass slowly moves to long wavelength as the stack expands due to the $x$-ray heating. At the point of failure the bandpass moves rapidly (in times of 100 to $200 \mathrm{psec}$ ) to long wavelength by several $\AA$, the reflectivity of the mirror then decays to zero on a time scale of 150 to $200 \mathrm{psec}$. The calculated response of the mirror is shown in Fig 3(b) from the ROMULS ${ }^{4}$ hydrodynamic simulation (to calculate the perturbation to the multilayer stack) using the XMAS ${ }^{11}$ post-processor (solves the Fresnel Equations to calculate the reflectivity of the perturbed multilayer). The simulation was performed with a damaging source that was a 500 psec pulse of $0.13 \mathrm{Jcm}^{-2}$ of $x$-rays with the same spectral shape as that used in the experiment. The data and the simulation are inconsistent in terms of both the early time expansion of the multilayer and the sudden break to long wavelength just after the peak of the damage pulse. Inspection of the simulation in detail shows that the expansion of the stack predicted by the ROMULS calculation is about a factor of two higher than book values for the expansion coefficients would indicate. The calculations show that the surface temperature of the mirror is at most $1100^{\circ} \mathrm{C}$ at the time when the mirror bandpass jumps to long wavelength. Furthermore the ROMULS calculation shows that the damage to the mirror is reversible. After the peak of the damage pulse the mirror starts to cool and the position of the mirror bandpass drifts back to its starting value. The rapid expansion seen in Fig 3(a) is not reversible as has been seen in experiments with very low fluences of $x$-rays where the expansion was halted and the mirror cooled before the decay of the reflectivity. ${ }^{2}$ Hence the expansion can be frozer into the structure of the mirror, implying a phase change of some type. The fadeout of the reflectivity after $t=2())$ psec in Fig 3(a) is also not reversible. Hence we conclude from this comparison that the ROMULS simulation is not describing the damage of carbon based multilayers very well. Fig. $3(\mathrm{c})$ is the result of a calculation using a simple model of the mirror damage mechanisms that will be discussed below.

\section{DISCUSSION}

Data similar to that shown in Figs 2 and 3 were obtained for, W/C, WRe/C, W( $/($, 3() .3 Stainless Steel/C and $\mathrm{Cr}_{3} \mathrm{C}_{2} / \mathrm{C}$ mirrors and the results reported in detail in Ref. 2 . The major conclusions were:

1) A phase change of some kind, probably graphitization of the carbon layer causes the expansion of the multilayer stack, causing the peak of the mirror bandpass to move 10 longer wavelength, at temperatures well below melting.

2) The expansion is depth graded due to the depth profile of absorbed $x$-rays, causing a gradient in layer spacing that reduces the peak reflectivty, and broadens the width of the bandpass.

3) After expansion to a peak value of $\sim 125 \%$ of the inicial period, the mirrors layer structure is destroyed. it was postulated that this was due to inter-diffusion of the metal and carbon layers, but at very low temperature $\left(\sim 1200^{\circ} \mathrm{C}\right)$.

4) $\mathrm{Cr}_{3} \mathrm{C}_{2} / \mathrm{C}$ multilayers had a factor of two higher damage threshold than any of the other mirrors.

5) $\mathrm{W} / \mathrm{C}, \mathrm{WRe} / \mathrm{C}$, and $\mathrm{WC} / \mathrm{C}$ all damaged in the same way and at about the same fluence, implying that the mirror damage is driven by the $\mathrm{C}$ layer.

6) The graphitization and inter-diffusion were both observed to be very rapid.

Considering these conclusions, a new multilayer mirror damage model was constructed to calculate realistic reflectivities. Initially the code propagates the incident $x$-ray spectrum into the test mirror and uses the energy deposition profile to calculate the mirror temperature as a function of depth and time accounting for thermal conductivity effects. Graphitization of each carbon layer is accounted for by assuming the maximum expansion of the amorphous carbon is $25 \%$ of 


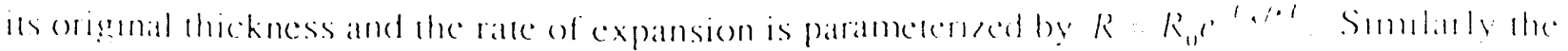
interdiffusion rate of the carbon layers with the metal layers of the mirror is modelled wilh an activation energy and a rate equation of the same form, producing the sudden destruction of the mirrors seen in experimental data. Comparing the reflectivity results from the model in figure $3($ (c) to the data in figure $3($ a) we observe that the morel closely follows the reflectivity shoft to

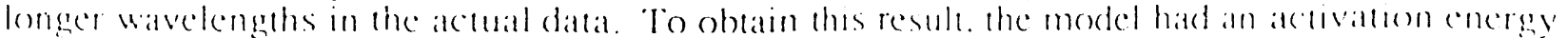

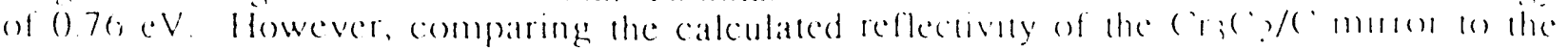
experoment? , the moxkel slightly overestimates the damage caused to the mumb

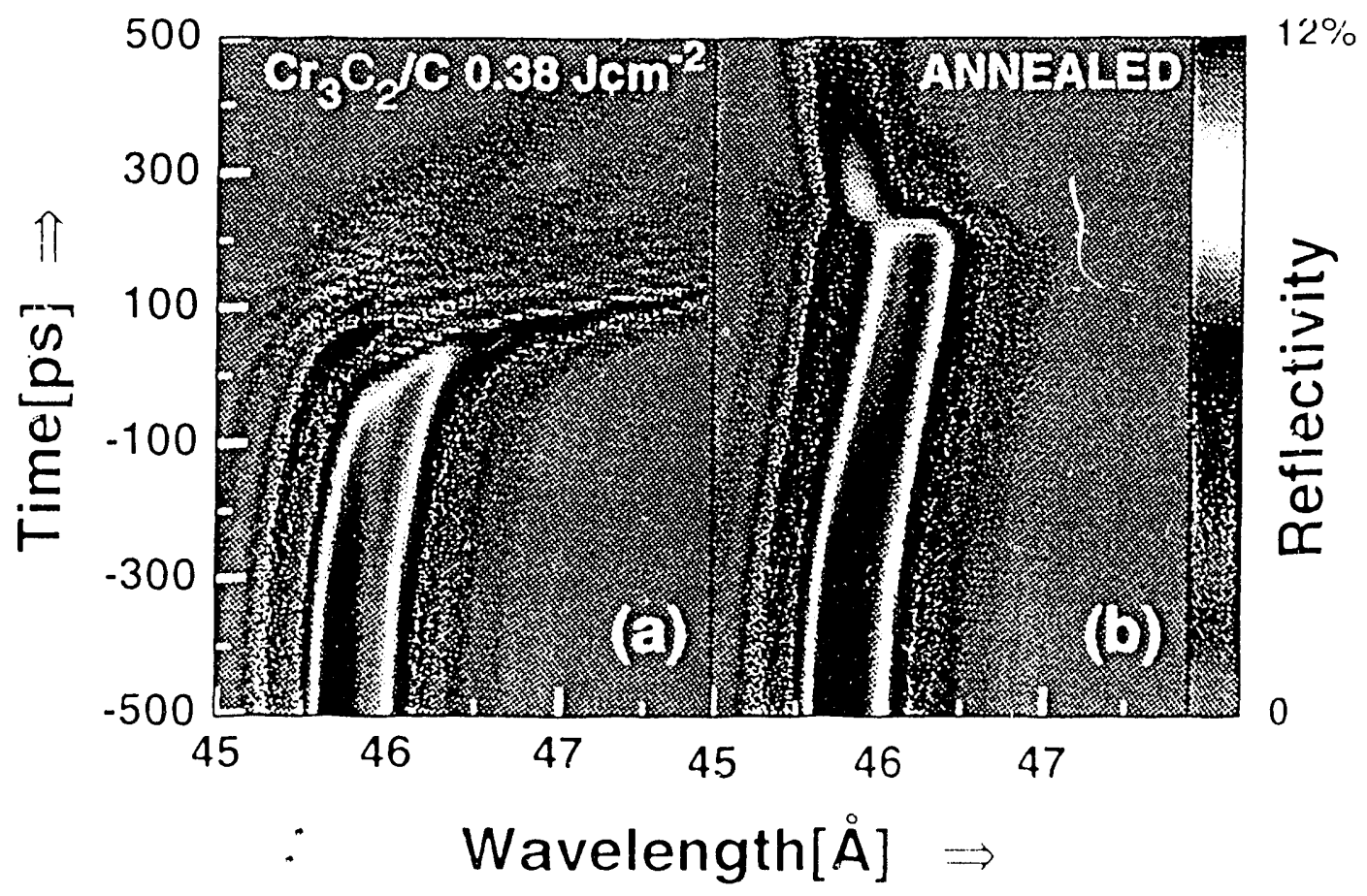

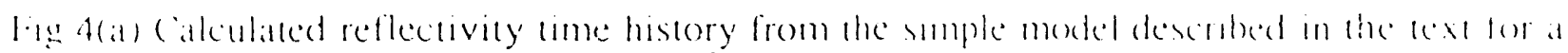
(

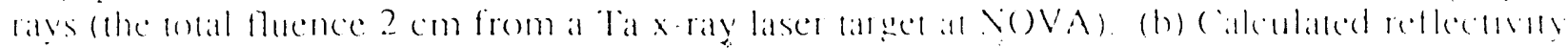

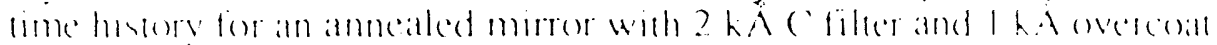

The smple mextel also calculates he heall transfer coffeces of placing a layer of filler matertal on fromt of the mimor, or in comber with the morror to ace as at heal sink. ()urpul from dhese calculations is avallable m the form of emperature profiles, density proiles ame resolved reflectivily datat, of ceflectivas lane outs. Lxarapolating form our sucesstul modelong. we can then use al as a gurbe for new mirror designs, the mose

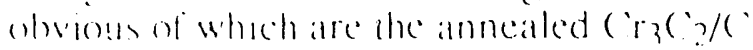

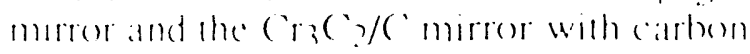
avereasis

The reflectorly ame history shown m figure that is calculated with a $2 \mathrm{k} \AA$ c foller placed on the path of the damaging $x$ rays and a 1 hid overcoat of $C$ applied direcoly io the surface of the mirror to act as a heall sumk. For ligure $4(b)$ the conditions are identeal exeept that the mirror has been annealed prior an calculating the reflectivity.

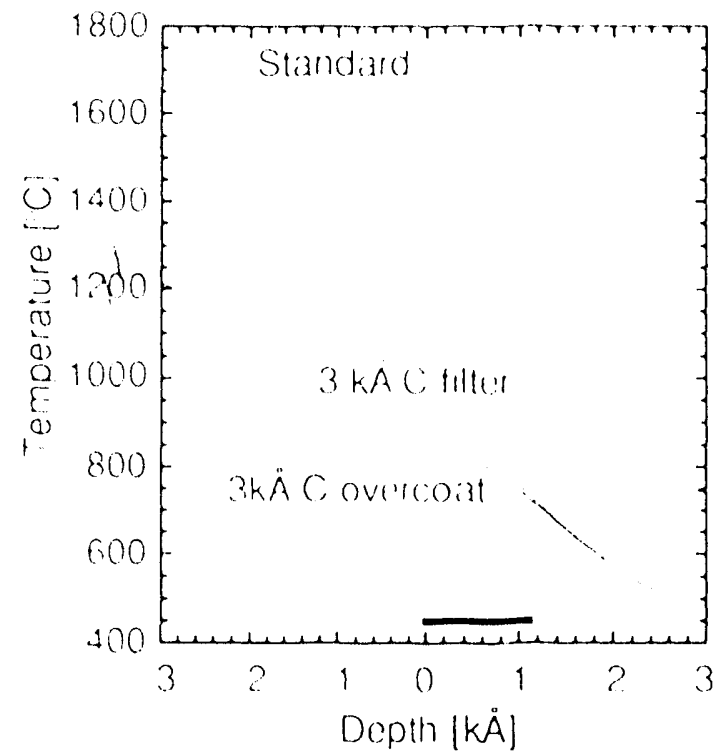

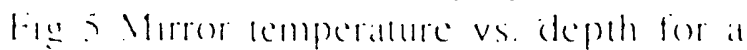

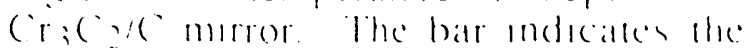

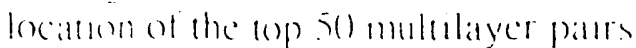


Note the higher predicted damage threshold for the annealed mirror. Graphitizing the C layers by annealing the mirror before its use offers the advantage of a stationary reflectivity bandpass until interdiffusion occurs. The model also predicts that placing the carbon filtering in contact with the mirror surface is more beneficial to lowering the surface temperature of the mirror than filtering above the surface of the mirror, even in a situation of decreased heat conductivity. Figure 5 shows mirror temperature as a function of depth for a $\mathrm{Cr}_{3} \mathrm{C}_{2} / \mathrm{C}$ mirror with and without a carbon overcoat.

\section{CONCLUSION}

Most promising for robust multilayer optics is the $\mathrm{Cr}_{3} \mathrm{C}_{2} / \mathrm{C}$ mirror due to its factor of 2 higher damage threshold above the other mirrors tested. 2 This higher damage threshold is probably due to the average higher heat capacity of the $\mathrm{Cr}_{3} \mathrm{C}_{2} / \mathrm{C}$ multilayer mirror (about twice as large as other mirrors tested) which keeps the carbon layers cooler, and hence delays the interdiffusion of the mirror layer pairs. The new multilayer mirror damage model shows good agreement with damaged mirror data, and predicts reduced mirror damage for carbon heat sink coatings and annealed mirrors. To test the reliability of the new mirror model predictions, it will be necessary to perfnrm more multilayer mirror damage experiments examining the effects of carbon overcoats and annealing on $\mathrm{x}$-ray damage to multilayer mirror reflectivity. $\mathrm{Cr}_{3} \mathrm{C}_{2} / \mathrm{C}$ mirrors and annealed mirrors are highly attractive low-damage test subjects at our wavelengths, and should be investigated thoroughly.

We acknowledge the support of the Nova Experiments Group and the staff at the Physics Research Laser. This work was performed under the auspices of the US. Department of Energy by the Lawrence Livermore National Laboratory under contract No. W-7405-ENG-48.

\section{REFERENCES}

IB. J. MacGowan, S. Maxon, L. B. Da Silva, D. J. Ficlds, C. J. Kcane, D. L. Mathews, A. L.. Osterheld, J. H. Scoficld, G. Shimkaveg, and G. F. Stone, Demonstration of $x$-ray amplefiers near the carbon $K$ edge, Phy's. Rev. Lell., 65, 420) (1990), and UCRL-JC-103605 (April 199()).

2B.J. MacGowan, S. Mrowka, T. Barbec, L. Da Silva, D. Eder, J. Koxh, L. Pan, J. Turner, J. Underwood, and P. Young, Investigation of dumage to multilayer optics in $x$-ray laser cavilie's: W/l'. WRe/l: W'ClC. Siainless Steel/C, and $\mathrm{Cr}_{3} \mathrm{C}_{2} / C$ mirrors, J. X-ray Science and Technology, 3, 231 (1993).

${ }^{3}$ M.P. Hockaday, R.L. Blake, J.S. Grosso, M.M. Selph, M.M. Klcin, W. Matuska, Jr., M.A. Palmer, and R.J. Liefeld, Preliminary investigation of changes in $x$-ray multilayer optics subjected to high radiation flux, in Applications of thin film multilayered structures to figured $x$-ray optics. G.F. Marshall ed., SPIE Proceedings 563, 61 (1985), and M. Hockaday, An experimental measurement of metal multilayer x-ray reflectivity degradation due to intense x-ray flux. Ph.D. Thesis, New Mexico State University, available as Los Alamos National Laboratory publication, L.A-10989-T, (1987).

${ }^{4}$ K.J. Gray, L.V. Knight, B.G. Peterson, J.M. Thorne, T.W. Bartece, Jr., and A. Toor, Laser plasma damage to multilayer mirrors, in X-rays from laser plasmas, M.C. Richardson cd., SPIE Procecdings 831, 136 (1987), and K.J. Gray, B.G. Peterson, L.V. Knight, and J.M. Thorne, Simulated response of multilaver x-ray refle'ters 10 damaging fluxes, Comput. Phys. 3(4), 65, (1989), and K.J. Gray, Simulaled and medsured response of robust multilayer x-ray reflectors, Ph.D. Thesis, Brigham Young University, (1989).

${ }^{5}$ L.V. Knight, K.J. Gray, B.G. Petcrson, J.M. Thome and R.T. Perkins, Study of multilayers subjected to intense radiation, in Soft $x$-ray optics and technology, E.E. Koch and h. Schmahl eds., SPIE: Procecdings 733. $410(1986)$,

${ }^{6} D$. Kohler, J.L. Guttman, B.A. Watson, and M. Gerassimenko, P'ulsed $x$-ray induced damage to metal and multilayer mirrors, Rev. Sc. Instr. 56, 812 (1985). These experiments are described in more detail in: B.A. Watson, D.A. Kohler, and J.L. Guttman, The response of multilayer films and mirrors to intense x-irradication, available as University of California, Lawrence Livermore National Laboratory Publication UCRL,-15.596, (1984).

${ }^{7}$ A. Zigler, J.H. Underwood, J. Zhu, and R.W. Falcone, Rapid lattice expansion and increased $x$-ray reflectivily of a multilayer structure due to pulsed laser heating. Appl. Phys. Lett. 51, 1873, (1987).

${ }^{8}$ E. Spiller and A.E. Rosenbluth, Determination of thickness errors and boundary roughess from the medsisted performance of a multilayer coating. Opt. Eng. 25, 954 (1986).

${ }^{9} \mathrm{~T}$. Kita, el. al., Mechanically ruled aberration-corrected concave gratings for a flal-field grazing-incidence spectrograph, Appl. Opt. 22, 512 (1983), and G. P. Kichn, O. Willi, A. R. Damercll, and M.H. Key. Novel time-resolved VUV spectrograph for x-ray laser research, App. Opt., 26, 425 (1987).

${ }^{10}$ D. R. Kania, et. al., Absolute $x$-ray power measurements with subnanosecond time resolution using type lla diamond photoconduclors, J. Appl. Phys. 68, 124-130 (1990).

'1'S. Mrowka, XMAS apcriodic stack multilayer performance calculation, unpublished (1992). 

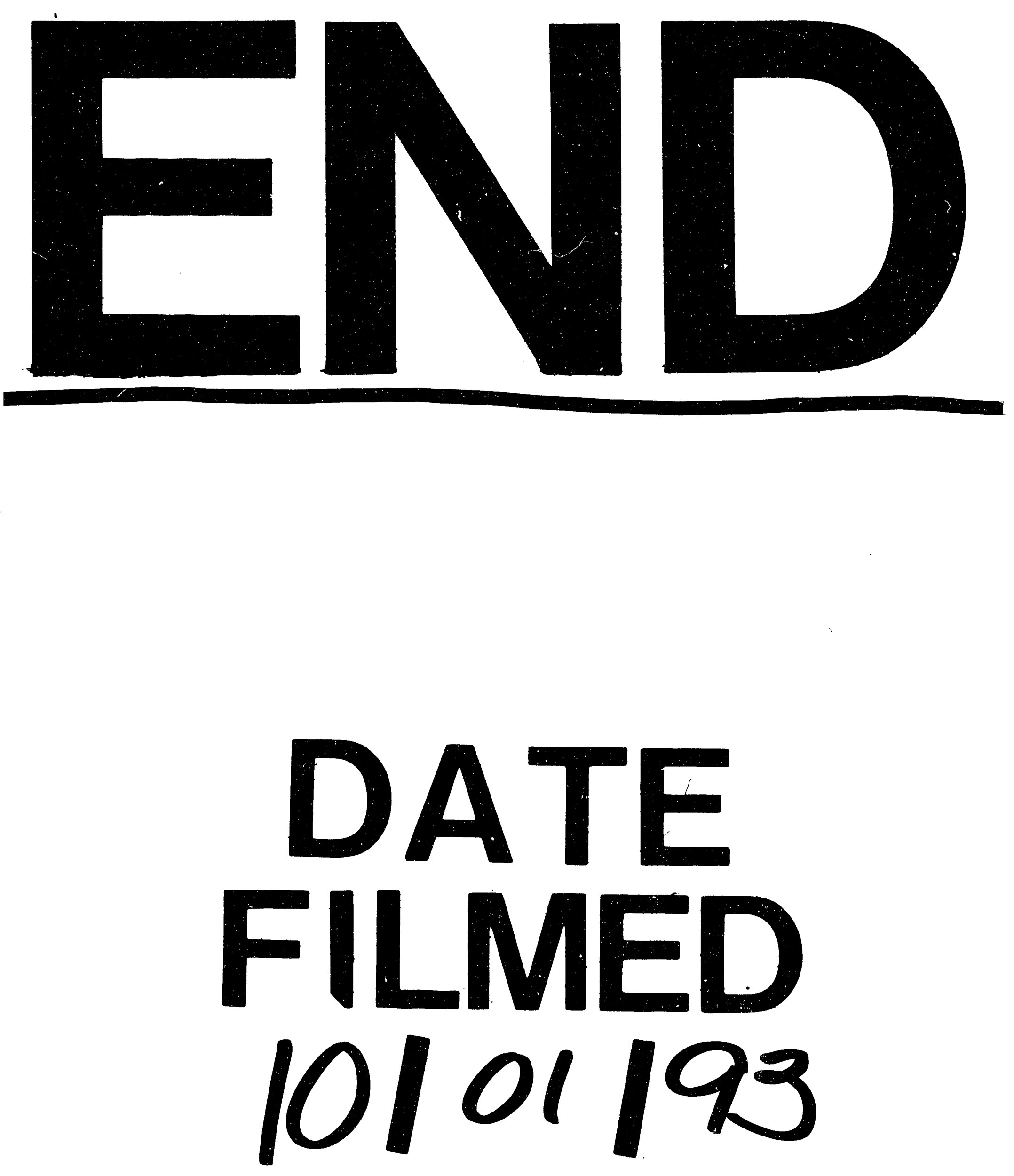
